\title{
Palmitoylethanolamide Dampens Reactive Astrogliosis and Improves Neuronal Trophic Support in a Triple Transgenic Model of Alzheimer's Disease: In Vitro and In Vivo Evidence
}

\author{
Maria Rosanna Bronzuoli, ${ }^{1}$ Roberta Facchinetti, ${ }^{1}$ Luca Steardo Jr., ${ }^{2}$ Adele Romano $\mathbb{D}^{1},{ }^{1}$ \\ Claudia Stecca, ${ }^{1}$ Sergio Passarella, ${ }^{1}$ Luca Steardo, ${ }^{1}$ Tommaso Cassano ${ }^{D},{ }^{3}$ \\ and Caterina Scuderi ${ }^{1}$
}

${ }^{1}$ Department of Physiology and Pharmacology "V. Erspamer", Sapienza University of Rome, Rome, Italy

${ }^{2}$ Department of Psychiatry, University of Naples SUN, Naples, Italy

${ }^{3}$ Department of Clinical and Experimental Medicine, University of Foggia, Foggia, Italy

Correspondence should be addressed to Tommaso Cassano; tommaso.cassano@unifg.it

Received 25 May 2017; Revised 2 October 2017; Accepted 23 October 2017; Published 16 January 2018

Academic Editor: Bruno Meloni

Copyright (c) 2018 Maria Rosanna Bronzuoli et al. This is an open access article distributed under the Creative Commons Attribution License, which permits unrestricted use, distribution, and reproduction in any medium, provided the original work is properly cited.

\begin{abstract}
Alzheimer's disease (AD) is a neurodegenerative disorder responsible for the majority of dementia cases in elderly people. It is widely accepted that the main hallmarks of $\mathrm{AD}$ are not only senile plaques and neurofibrillary tangles but also reactive astrogliosis, which often precedes detrimental deposits and neuronal atrophy. Such phenomenon facilitates the regeneration of neural networks; however, under some circumstances, like in $\mathrm{AD}$, reactive astrogliosis is detrimental, depriving neurons of the homeostatic support, thus contributing to neuronal loss. We investigated the presence of reactive astrogliosis in $3 \times \mathrm{Tg}-\mathrm{AD}$ mice and the effects of palmitoylethanolamide (PEA), a well-documented anti-inflammatory molecule, by in vitro and in vivo studies. In vitro results revealed a basal reactive state in primary cortical $3 \times \mathrm{Tg}$ - $\mathrm{AD}$-derived astrocytes and the ability of $\mathrm{PEA}$ to counteract such phenomenon and improve viability of $3 \times \mathrm{Tg}-\mathrm{AD}$-derived neurons. In vivo observations, performed using ultramicronized- (um-) PEA, a formulation endowed with best bioavailability, confirmed the efficacy of this compound. Moreover, the schedule of treatment, mimicking the clinic use (chronic daily administration), revealed its beneficial pharmacological properties in dampening reactive astrogliosis and promoting the glial neurosupportive function. Collectively, our results encourage further investigation on PEA effects, suggesting it as an alternative or adjunct treatment approach for innovative $\mathrm{AD}$ therapy.
\end{abstract}

\section{Introduction}

Alzheimer's disease (AD) accounts for more than $80 \%$ of dementia cases worldwide in elderly people and leads to the progressive loss of mental, behavioral, and learning abilities and to functional decline [1]. Histopathologically, AD is characterized by two major protein deposits affecting mainly hippocampal and cortical regions: extracellular neuritic $\beta$-amyloid peptide $(\mathrm{A} \beta)$, which induces the creation of senile plaques (SPs), and the production of intracellular neurofibrillary tangles (NFTs) due to tau hyperphosphorylation that occupies much of the cytoplasm of pyramidal neurons [2, 3]. The presence of abnormally activated microglia and astrocytes is a feature of $\mathrm{AD}$ of more recent discovery [4]. It is followed by an intense inflammation, closely associated with amyloid deposits in the brain parenchyma $[4,5]$. Indeed, studies of post mortem brain tissues from $\mathrm{AD}$ patients demonstrated the presence of a generalized astrogliosis, mainly manifested by astrocytic dysfunction, detectable by an increased expression of both glial fibrillary acidic protein (GFAP) and S100B, and accompanied by an increased production of proinflammatory mediators [6]. Many authors name this complex phenomenon as reactive astrogliosis $[6,7]$. GFAP is a specific cytoskeletal 
marker, whose expression is higher during astrogliosis [8]. $\mathrm{S} 100 \mathrm{~B}$ is a neurotrophin that, at physiological concentrations (nanomolar), exerts prosurvival effects on neurons and stimulates neurite outgrowth [9]. However, at higher (micromolar) concentrations, S100B becomes neurotoxic, promoting inflammation and neuronal apoptosis [10]. A $\beta$ itself induces the expression of proinflammatory cytokines by glial cells [11] and the induction of proinflammatory enzymes, such as the inducible nitric oxide synthase (iNOS) and the isoenzyme cyclooxygenase type-2 (COX2). Several lines of evidence suggest that all these factors may contribute to neuronal dysfunction and cell death, either alone or in concert [12]. The reactive astrogliosis has the initial intent of defence of removing injurious stimuli. However, if this phenomenon goes beyond physiological control, it may cause several detrimental effects. Under these circumstances, both neuronal and synaptic loss are detectable, because structural and functional modifications of neurons and astrocytes occur $[13,14]$. Alterations of the neuronal marker microtubule-associated protein 2 (MAP-2), as well as modifications of the neurotrophin brain-derived neurotrophic factor (BDNF) content, have also been demonstrated $[15,16]$. Considering the crucial actions of BDNF, especially in controlling neuronal survival, differentiation, neurotransmitter release, dendritic remodeling, axon growth, and synaptic plasticity $[17,18]$, the detrimental consequences of its alterations by reactive astrogliosis may be dramatic.

Based on this evidence, it is reasonable to assume that an early combination of neuroprotective and anti-inflammatory treatments may represent an efficacious approach to counteract $\mathrm{AD}$. In this context, palmitoylethanolamide (PEA), an endogenous lipid mediator, seems to be a promising pharmacological agent. The anti-inflammatory and neuroprotective effects of PEA, as well as its ability to attenuate memory impairment in surgical models of $\mathrm{AD}$, have already been demonstrated [15, 19-22].

In this work, we provide novel evidence on the ability of PEA to counteract reactive astrogliosis and neuronal impairment both in vitro and in vivo. For the in vitro studies, we used primary cortical neurons and astrocytes from $3 \times \mathrm{Tg}-\mathrm{AD}$ mice, a triple transgenic model of $\mathrm{AD}$ currently considered the closest to the familial human disease, and from wild-type littermates (non-Tg). The same AD model was used for the in vivo experiments, in which male 3 -month-old $3 \times \mathrm{Tg}-\mathrm{AD}$ and sex- and age-matched non- $\mathrm{Tg}$ mice were subcutaneously implanted with a pellet, releasing either ultramicronized-PEA (um-PEA) or placebo, for three months. This treatment schedule was designed to reproduce a chronic treatment (as needed for this type of disease), administered starting from the early stage of the $\mathrm{AD}$ pathology.

In vitro results highlighted an intense activation and inflammation in primary $3 \times \mathrm{Tg}-\mathrm{AD}$ astrocytes, as well as the ability of PEA to counteract them and promote neuronal viability. Moreover, in vivo biochemical experiments demonstrated that chronic um-PEA treatment resulted in a beneficial control of the astrocyte activation and neuroinflammation. In addition, um-PEA interestingly increased BDNF levels, confirming its neuroprotective/neurotrophic effects.

Our results confirm the therapeutic potential of PEA, demonstrating its ability to counteract some of the detrimental effects occurring in $\mathrm{AD}$, since the earliest stage of the pathology. PEA is already on the market for the treatment of pain. Therefore, these observations, in addition to the information regarding its safety and tolerability also in humans, prompt us to hypothesize a rapid translation into clinical practice.

\section{Materials and Methods}

All the procedures involving animals were conducted in conformity with the guidelines of the Italian Ministry of Health (D.L. 26/2014) and performed in compliance with the European Parliament directive 2010/63/EU.

2.1. Animals and Experimental Design. $3 \times \mathrm{Tg}-\mathrm{AD}$ mice [23] expressing $\mathrm{APP}_{\text {swe }}, \mathrm{PS}_{\mathrm{M} 146 \mathrm{~V}}$, and tau $\mathrm{P}_{\mathrm{P} 31 \mathrm{~L}}$ human transgenes were compared to non-Tg littermates. The background strain of 3xTg-AD mice was C57BL6/129SvJ hybrid [23]. Animals were group housed and raised in controlled conditions $\left(22 \pm 2^{\circ} \mathrm{C}\right.$ temperature, $12 \mathrm{~h}$ light $/ 12 \mathrm{~h}$ dark cycle, $50 \%-60 \%$ humidity) in an enriched environment, with food and water ad libitum.

For in vitro experiments, we used newborn mice at postnatal day (PND) 1 or 2 . Astrocytes were isolated from both non- $\mathrm{Tg}$ (total pups used $=12$ ) and $3 \times \mathrm{Tg}-\mathrm{AD}$ (total pups used $=24)$ mice. Neurons were isolated from $3 \times \mathrm{Tg}-\mathrm{AD}$ mice (total pups used $=12$ ).

For in vivo experiments, 3-month-old male non-Tg $(n=18)$ and $3 \times \mathrm{Tg}-\mathrm{AD}(n=18)$ mice were used. Animals were surgically implanted with a 90-day-release pellet containing either $28 \mathrm{mg}$ um-PEA, a formulation that improves its bioavailability [24], or placebo (catalogue number NX999 and NC-111, resp.; Epitech Group SpA). Both pellets were made by Innovative Research of America (Sarasota, Florida) that homogeneously distributed um-PEA in the matrix, keeping its original crystalline form of micrometric size. Therefore, mice received $10 \mathrm{mg} / \mathrm{kg} / \mathrm{day}$ for 3 consecutive months. Experimental dosage was chosen according to literature $[25,26]$.

To subcutaneously implant the pellet, mice were anesthetized with ketamine hydrochloride $(1 \mathrm{mg} / 10 \mathrm{~g})$ and xylazine $(0.1 \mathrm{mg} / 10 \mathrm{~g})$. After shaving the shoulder blades, the implantation area was sterilized with $70 \%$ alcohol. A dorsal midline incision of $1-2 \mathrm{~cm}$ was executed to create a subcutaneous pocket with a blunt probe. One pellet, containing um-PEA or placebo, was placed into the pocket and the surgical incision was closed with sterile absorbable sutures. Non-Tg and $3 \times \mathrm{Tg}-\mathrm{AD}$ mice were then left in their home cages for the next three months, and their weight monitored daily. No weight differences among all experimental groups were detected (data not shown). At the end of the chronic treatment, 6month-old mice were killed by decapitation, and their brains were rapidly excised and either immediately frozen on dry ice for the immunofluorescence experiments or freshly dissected 


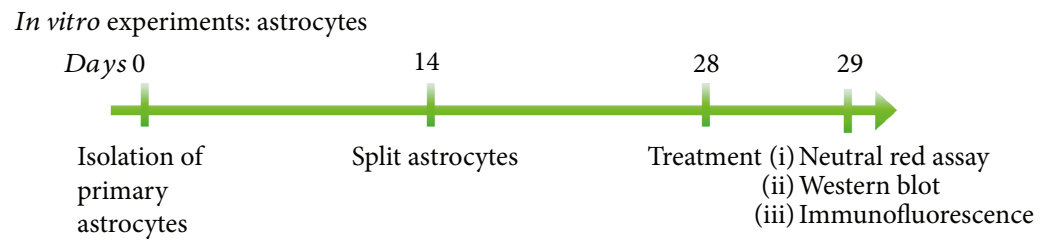

(a)

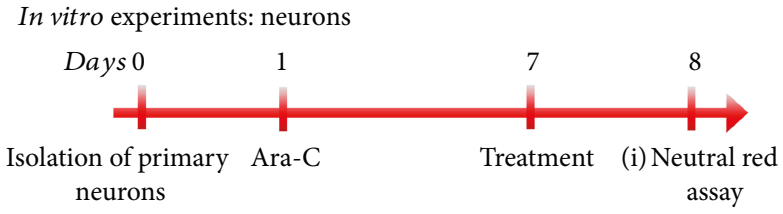

(b)

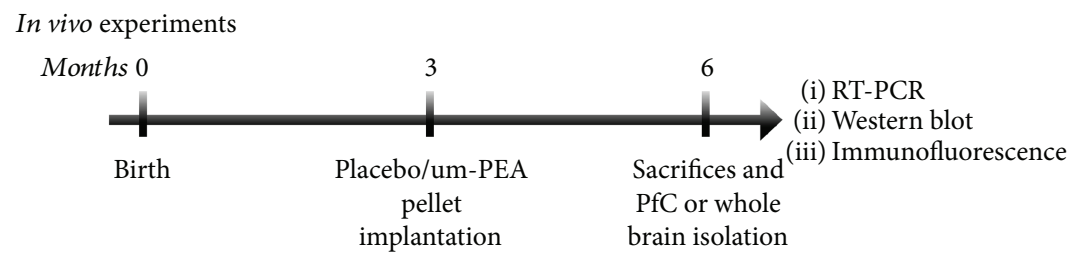

(c)

Figure 1: Study designs. Schematic representation of the experimental designs in (a) primary $3 \times \mathrm{Tg}-\mathrm{AD}$ and non-Tg astrocytes, (b) primary $3 \times \mathrm{Tg}-\mathrm{AD}$ neurons, and (c) in vivo experiments in $3 \times \mathrm{Tg}-\mathrm{AD}$ and non-Tg mice.

to isolate the frontal cortex (FC) for RT-PCR and Western blot analyses.

The experimental timelines are summarized in Figure 1.

2.2. Astroglial Primary Cultures. Astroglial primary cultures were obtained as previously described [27]. Cortices were isolated from non-Tg and $3 \times \mathrm{Tg}-\mathrm{AD}$ newborn mice (PND 1 or 2) sacrificed by decapitation. Tissues were manually homogenized in Dulbecco's modified Eagle's medium (DMEM) supplemented with 5\% inactivated fetal bovine serum (FBS), $100 \mathrm{U} / \mathrm{ml}$ penicillin and $100 \mu \mathrm{g} / \mathrm{ml}$ streptomycin and then chemically dissociated with a solution containing $0.25 \%$ trypsin, $0.2 \%$ ethylenediaminetetraacetic acid (EDTA), and $0.2 \mathrm{mg} / \mathrm{ml}$ of DNAse I (all from Sigma-Aldrich, Milan, Italy) to obtain single cells. After a centrifugation at $403 \times \mathrm{g}$ for 5 minutes, the medium was replaced, and surviving cells were counted using a Burker chamber with a $0.2 \%$ trypan blue solution and seeded at a density of $3 \times 10^{-6}$ cells $/ 75 \mathrm{~cm}^{2}$ flask. Cell cultures were at $+37^{\circ} \mathrm{C}$ in humidified atmosphere containing $5 \% \mathrm{CO}_{2}$. DMEM supplemented with $20 \%$ inactivated FBS and $100 \mathrm{U} / \mathrm{ml}$ penicillin, and $100 \mu \mathrm{g} / \mathrm{ml}$ streptomycin was replaced $24 \mathrm{~h}$ and one week after isolation. Approximately 14-15 days after the dissection, when a monolayer of cells was created, astrocytes were separated from microglia by mechanical shacking. Then, astrocytes were detached from the plates with a solution containing $0.25 \%$ trypsin and $0.2 \%$ EDTA and then seeded into $10 \mathrm{~cm}$ diameter petri dishes at a density of $1 \times 10^{6}$ cells/ dish for Western blot analysis, into eight chambers polystyrene culture slides at a density of $3 \times 10^{4}$ cells/chamber (Thermo Fisher Scientific, MA, USA) for immunofluorescence, or into 24 -well plates at a density of $1 \times 10^{5}$ cells/well for neutral red viability assay. Experiments were performed
28 days after cells isolation, when astrocytes are considered completely mature [22].

2.3. Neuronal Primary Cultures. Cortices from newborn $3 \times \mathrm{Tg}$-AD mice (PND 1 or 2 ) were used to obtain primary neuronal cultures as previously described [20]. Multiwells were previously coated with poly-L-lysine (Sigma-Aldrich) to allow neurons to adhere to the bottom of the wells. Mice were sacrificed by decapitation and cerebral cortices dissected in Hank's balanced salt solution (HBSS) containing $25 \mathrm{mM}$ 4-(2-hydroxyethyl)-1-piperazineethanesulfonic acid (Hepes), $100 \mathrm{U} / \mathrm{ml}$ penicillin, and $100 \mu \mathrm{g} / \mathrm{ml}$ of streptomycin in cold conditions. Tissues were mechanically and chemically homogenized in a solution containing $0.25 \%$ trypsin, $0.2 \%$ EDTA, and $0.2 \mathrm{mg} / \mathrm{ml}$ of DNAse I (all from Sigma). After a centrifugation at $403 \times \mathrm{g}$ for 5 minutes, cells were suspended in neurobasal media supplemented with $2 \%$ B27, $100 \mathrm{U} / \mathrm{ml}$ penicillin, and $100 \mu \mathrm{g} / \mathrm{ml}$ streptomycin. Then, they were counted using a Burker chamber while suspended in $0.2 \%$ trypan blue solution and then seeded in 24-well multiplates at a density of $5 \times 10^{-5}$ cells/well. Neuronal cultures were maintained at $+37^{\circ} \mathrm{C}$ in humidified atmosphere containing $5 \% \mathrm{CO}_{2}$. Twenty-four hours later, cells were treated with $10 \mu \mathrm{M}$ of cytosine arabinoside (ara-C) to suppress glial cell growth. One week later, primary $3 \times \mathrm{Tg}-\mathrm{AD}$-derived neurons were treated with PEA.

2.4. Chemicals and Cell Treatments. Mature astrocytes and neurons derived from $3 \times \mathrm{Tg}-\mathrm{AD}$ mice were treated with PEA (Epitech Group SpA, Saccolongo, Italy), at three different concentrations $(0.01,0.1$, and $1 \mu \mathrm{M})$, chosen according to our previous works $[19,20,22]$. PEA was suspended in $5 \%$ pluronic F-68 (Sigma-Aldrich) and solubilized in $95 \%$ 
TABLE 1: Experimental conditions for immunofluorescence.

\begin{tabular}{lcccc}
\hline $\begin{array}{l}\text { Primary } \\
\text { antibody }\end{array}$ & $\begin{array}{c}\text { Brand primary } \\
\text { antibody }\end{array}$ & $\begin{array}{c}\text { Primary antibody } \\
\text { dilution }\end{array}$ & Secondary antibody & $\begin{array}{c}\text { Brand secondary } \\
\text { antibody }\end{array}$ \\
\hline Rabbit $\alpha$-GFAP & Abcam & $1: 10000.5 \%$ BSA in & FITC conjugated goat anti-rabbit IgG (H+L) $1: 200$, & Jackson \\
& TBS/0.25\% triton X-100 & $0.5 \%$ BSA in TBS/0.25\% triton X-100 & ImmunoResearch \\
Rabbit $\alpha$-S100B & Novus & $1: 2500.5 \%$ BSA in & TRITC conjugated goat anti-rabbit IgG (H+L) $1: 200$, & Jackson \\
& Biologicals & TBS/0.25\% triton X-100 & 0.5\% BSA in TBS/0.25\% triton X-100 & ImmunoResearch \\
Mouse $\alpha$-MAP2 & Novus & $1: 2500.5 \%$ BSA in & TRITC conjugated goat anti-mouse IgG (H+L) $1:$ & Jackson \\
& Biologicals & TBS/0.25\% triton X-100 & 200, 0.5\% BSA in TBS/0.25\% triton X-100 & ImmunoResearch \\
\hline
\end{tabular}

DMEM. First, we added pluronic F-68 to PEA powder and sonicated the emulsion for $20 \mathrm{~min}$ protecting it from light, and then we included DMEM to complete the solution. Viability assay, Western blot analysis, and immunofluorescence were performed $24 \mathrm{~h}$ after treatments.

2.5. Analysis of Astrocyte and Neuronal Viability by Neutral Red Uptake Assay. Astrocyte and neuronal viability was tested $24 \mathrm{~h}$ after treatment by neutral red uptake assay, as previously described [27]. Cells were incubated with a neutral red working solution, containing $50 \mu \mathrm{g} / \mathrm{ml}$ in $\mathrm{Ca}^{2+}$ and $\mathrm{Mg}^{2}$ free PBS (Sigma-Aldrich), for $3 \mathrm{~h}$ at $+37^{\circ} \mathrm{C}$. Cells were then rinsed in $\mathrm{Ca}^{2+}$ - and $\mathrm{Mg}^{2}$-free PBS and the dye removed from the inside of the cells through a rinse in destaining solution (ethanol:deionized water: glacial acetic acid, 50:49:1 v/v). The absorbance, whose value is proportional to the number of living cells, was read at $540 \mathrm{~nm}$ using a microplate spectrophotometer (Epoch, BioTek, Winooski, VT, USA). The values obtained were referred to control medium-exposed cultures (CTRL) and expressed as percentage variation of CTRL. Three independent experiments were performed in triplicate.

2.6. Immunofluorescence. Both primary astrocytes, $24 \mathrm{~h}$ after treatment, and non-Tg and $3 \times \mathrm{Tg}-\mathrm{AD}$ coronal slices $(12 \mu \mathrm{m}$ thickness), deriving from 6-month-old mice containing the FC, were rinsed in PBS and postfixed for 10 minutes at $+4^{\circ} \mathrm{C}$ with $4 \%$ paraformaldehyde (PFA) prepared in PBS. Then, samples were blocked with $1 \%$ bovine serum albumin (BSA) prepared in PBS/0.25\% triton X-100 for 90 minutes at room temperature. Cells were incubated overnight at $+4^{\circ} \mathrm{C}$ in $0.5 \%$ BSA in Tris-buffered saline (TBS) $/ 0.25 \%$ triton X-100 solution containing the primary antibodies rabbit antiGFAP (1:1000, Abcam, Cambridge, USA) or rabbit antiS100B ( $1: 250$, Novus Biologicals, Littleton, CO, USA). FC slices, instead, were incubated overnight at $+4^{\circ} \mathrm{C}$ with mouse anti-MAP2 ( $1: 250$, Novus Biologicals, Littleton, CO, USA) in $0.5 \% \mathrm{BSA}$ in $\mathrm{TBS} / 0.25 \%$ triton $\mathrm{X}-100$ solution. The following day, cells and tissues were thoroughly rinsed in PBS and then incubated for 2 hours at room temperature with the appropriate secondary antibody (fluorescein- (FITC-) conjugated AffiniPure goat anti-rabbit IgG $(\mathrm{H}+\mathrm{L})$, rhodamine- (TRITC-) conjugated AffiniPure goat anti-rabbit IgG $(\mathrm{H}+\mathrm{L}), 1: 200$, or rhodamine- (TRITC-) conjugated AffiniPure goat anti-mouse IgG $(\mathrm{H}+\mathrm{L})$; Jackson ImmunoResearch, Suffolk, UK). Nuclei were stained with 4',6-diamidino-2-phenylindole, dihydrochloride (DAPI) (1:75000, Sigma-Aldrich) in $0.5 \%$ BSA in TBS/0.25\% triton X-100, added to the solution of the secondary antibodies. Samples were rinsed with PBS and coverslipped using Fluoromount aqueous mounting medium (Sigma-Aldrich). Experimental conditions are summarized in Table 1.

Pictures were captured with a wide-field microscope (Eclipse E600; Nikon Instruments, Rome, Italy) and densitometric analysis performed using ImageJ software. Data are expressed as ratio $\left(\Delta F / F_{0}\right)$ of the difference between the mean of fluorescence sample and its background $(\Delta F)$ and the nonimmunoreactive regions $\left(F_{0}\right)$. To prevent the observation of differences among experimental groups due to artifacts, the exposure parameters, such as gain and time, were kept constant during image acquisitions. For each analysis, three replicates were used, and at least three independent experiments were performed.

2.7. RNA Isolation and RT-PCR. Total mRNA from FC of both non-Tg and $3 \times \mathrm{Tg}-\mathrm{AD}$ mice was extracted using the NZY total RNA isolation kit (NZYTech, Lisboa, Portugal) following the manufacturer's protocol. Total mRNA was quantified by Nanodrop 1000 spectrophotometer (Thermo Fisher Scientific, MA, USA). Revers transcription of $1 \mu \mathrm{g}$ mRNA was performed to obtain cDNA adding oligo(dT) and random primers to the first-strand cDNA synthesis kit (NZYTech, Lisboa, Portugal). All PCRs were performed using the supreme NZYTaq DNA polymerase (NZYTech, Lisboa, Portugal) in the presence of specific primers (Sigma-Aldrich) for the target genes: GFAP, GAPDH, S100B, iNOS, and COX-2. GAPDH was used as reference gene. Three independent experiments were performed in triplicate. Primer sequences and PCR details are reported in Table 2.

2.8. Protein Extraction and Western Blot Analysis. Western blot analysis was performed on protein extracts obtained from primary astrocytic cultures as well as from FC samples, as previously described [15]. Samples were suspended in icecold hypotonic lysis buffer containing $50 \mathrm{mM}$ Tris/ $\mathrm{HCl}$ $\mathrm{pH} 7.5,150 \mathrm{mM} \mathrm{NaCl}, 1 \mathrm{mM}$ EDTA, $1 \%$ triton $\mathrm{X}-100$, $1 \mathrm{mM}$ phenylmethylsulfonyl fluoride (PMSF), $10 \mu \mathrm{g} / \mathrm{ml}$ aprotinin, and $0.1 \mathrm{mM}$ leupeptin (all from Sigma-Aldrich). After 40 min of incubation at $+4^{\circ} \mathrm{C}$, homogenates were centrifuged at $18440 \times \mathrm{g}$ for $30 \mathrm{~min}$ and the supernatant collected and stored in aliquots at $-80^{\circ} \mathrm{C}$ until use. An equivalent 
TABle 2: Primer sequences used for RT-PCR.

\begin{tabular}{|c|c|c|c|c|}
\hline Sequence of interest & & Primer $5^{\prime} \rightarrow 3^{\prime}$ & Annealing temperature $\left({ }^{\circ} \mathrm{C}\right)$ & Number of cycles \\
\hline \multirow{2}{*}{ GFAP } & Forward & GAAGAGGGACAACTTTGCAC & \multirow{2}{*}{61} & \multirow{2}{*}{32} \\
\hline & Reverse & GCTCTAGGGACTCGTTCGTG & & \\
\hline \multirow{2}{*}{ S100B } & Forward & TAATGTGAGTGGCTGCGGAA & \multirow{2}{*}{63} & \multirow{2}{*}{32} \\
\hline & Reverse & CCTCACCAAGGGCTAAGCAG & & \\
\hline \multirow{2}{*}{ iNOS } & Forward & CAAGCTGATGGTCAAGATCCAGAG & \multirow{2}{*}{64} & \multirow{2}{*}{40} \\
\hline & Reverse & GTGCCCATGTACCAACCATTGAAG & & \\
\hline \multirow{2}{*}{ COX-2 } & Forward & GCTGTACAAGCAGTGGCAAA & \multirow{2}{*}{62} & \multirow{2}{*}{30} \\
\hline & Reverse & CCCCAAAGATAGCATCTGGA & & \\
\hline \multirow{2}{*}{ GAPDH } & Forward & GCTACACTGAGGACCAGGTTGTC & \multirow{2}{*}{64} & \multirow{2}{*}{30} \\
\hline & Reverse & CCATGTAGGCCATGAGGTCCAC & & \\
\hline
\end{tabular}

TABLE 3: Experimental conditions for Western blot from $3 \times \mathrm{Tg}-\mathrm{AD}$ mice astrocytes and FC.

\begin{tabular}{|c|c|c|c|c|}
\hline Primary antibody & $\begin{array}{l}\text { Brand primary } \\
\text { antibody }\end{array}$ & Dilution & Secondary antibody & $\begin{array}{c}\text { Brand secondary } \\
\text { antibody }\end{array}$ \\
\hline GFAP & Abcam & $\begin{array}{l}1: 500005 \% \text { milk } \\
\text { in TBS-T } 0.1 \%\end{array}$ & $\begin{array}{c}\text { HRP conjugated goat anti-rabbit } \\
\text { IgG } 1: 300005 \% \text { milk in TBS-T } 0.1 \%\end{array}$ & $\begin{array}{c}\text { Jackson } \\
\text { ImmunoResearch }\end{array}$ \\
\hline S100B & Novus Biologicals & $\begin{array}{c}1: 10005 \% \text { BSA in } \\
\text { TBS-T } 0.1 \%\end{array}$ & $\begin{array}{l}\text { HRP conjugated goat anti-rabbit } \\
\text { IgG } 1: 100005 \% \text { BSA in TBS-T } 0.1 \%\end{array}$ & $\begin{array}{c}\text { Jackson } \\
\text { ImmunoResearch }\end{array}$ \\
\hline $\mathrm{COX}-2$ & Cell Signaling & $\begin{array}{l}1: 10005 \% \text { milk in } \\
\text { TBS-T } 0.1 \%\end{array}$ & $\begin{array}{l}\text { HRP conjugated goat anti-rabbit } \\
\text { IgG 1: } 100005 \% \text { milk in TBS-T } 0.1 \%\end{array}$ & $\begin{array}{c}\text { Jackson } \\
\text { ImmunoResearch }\end{array}$ \\
\hline iNOS & Sigma-Aldrich & $\begin{array}{l}1: 80001 \% \text { BSA in } \\
\text { TBS-T } 0.1 \%\end{array}$ & $\begin{array}{l}\text { HRP conjugated goat anti-rabbit } \\
\text { IgG } 1: 100001 \% \text { BSA in TBS-T } 0.1 \%\end{array}$ & $\begin{array}{c}\text { Jackson } \\
\text { ImmunoResearch }\end{array}$ \\
\hline BDNF & Santa Cruz & $\begin{array}{c}1: 5005 \% \text { milk in } \\
\text { TBS-T } 0.1 \%\end{array}$ & $\begin{array}{l}\text { HRP conjugated goat anti-rabbit } \\
\text { IgG } 1: 100005 \% \text { milk in TBS-T } 0.1 \%\end{array}$ & $\begin{array}{c}\text { Jackson } \\
\text { ImmunoResearch }\end{array}$ \\
\hline MAP2 & Novus Biologicals & $\begin{array}{c}1: 2505 \% \text { BSA in } \\
\text { TBS-T } 0.1 \%\end{array}$ & $\begin{array}{l}\text { HRP conjugated goat anti-rabbit } \\
\text { IgG } 1: 100005 \% \text { BSA in TBS-T } 0.1 \%\end{array}$ & $\begin{array}{c}\text { Jackson } \\
\text { ImmunoResearch }\end{array}$ \\
\hline $\mathrm{A} \beta_{(1-42)}$ & Millipore & $\begin{array}{c}1: 10005 \% \text { BSA in } \\
\text { TBS-T } 0.1 \%\end{array}$ & $\begin{array}{l}\text { HRP conjugated goat anti-mouse } \\
\text { IgG } 1: 100005 \% \text { BSA in TBS-T } 0.1 \%\end{array}$ & $\begin{array}{c}\text { Jackson } \\
\text { ImmunoResearch }\end{array}$ \\
\hline$\beta$-actin & Santa Cruz & $\begin{array}{l}1: 15005 \% \text { milk in } \\
\text { TBS-T } 0.1 \%\end{array}$ & $\begin{array}{l}\text { HRP conjugated goat anti-rabbit } \\
\text { IgG } 1: 100005 \% \text { milk in TBS-T } 0.1 \%\end{array}$ & $\begin{array}{c}\text { Jackson } \\
\text { ImmunoResearch }\end{array}$ \\
\hline
\end{tabular}

amount of each sample $(50 \mu \mathrm{g})$, calculated by Bradford assay, was resolved through $12 \%$ acrylamide SDS-PAGE precast gels (Bio-Rad Laboratories, Segrate, Italy). Then, with a trans-blot SD semidry transfer cell (Bio-Rad Laboratories), proteins were transferred onto nitrocellulose membranes that were then blocked with $5 \%$ no-fat dry milk powder or $5 \%$ BSA in TBS $0.1 \%$ Tween 20 (TBS-T) (Tecnochimica Moderna, Rome, Italy) for $1 \mathrm{~h}$ before overnight incubation at $+4^{\circ} \mathrm{C}$ with the appropriate primary antibodies. After appropriate rinses in $0.05 \%$ TBS-T, membranes were incubated for $1 \mathrm{~h}$ at room temperature with a specific secondary horseradish peroxidase- (HRP-) conjugated antibody. The experimental conditions are summarized in Table 3.

Immunocomplexes were detected by an ECL kit (GE Healthcare Life Sciences, Milan, Italy), exposed to X-ray film (GE Healthcare Life Sciences, Milan, Italy) and quantified using ImageJ software. Protein expression level of $\beta$-actin was used as loading control. For each antibody, three replicates were used, and at least three independent experiments were performed.
2.9. Statistical Analysis. Analysis was performed using GraphPad Prism software (GraphPad Software, San Diego, CA, USA). Student's $t$-test was used to compare two groups. One-way analysis of variance (ANOVA) was used to determine statistical differences among experimental groups in in vitro experiments. In vivo results were analyzed by two-way ANOVA, with genotype and treatment as factors. Bonferroni's post hoc test was used upon detection of a main significant effect. Differences between mean values were considered statistically significant when $P<0.05$.

\section{Results}

3.1. $3 \times T g-A D$ Primary Astrocytes Present Reactive Astrogliosis. Reactive astrogliosis is a phenomenon commonly detectable in $\mathrm{AD}$ brains and characterized by both astrocyte activation and neuroinflammation [6]. Here, we decided to test parameters connected with such events in both non-Tg and $3 \times \mathrm{Tg}-\mathrm{AD}$ primary astrocytes. 
To study astrocyte activation, we tested the expression of GFAP, a specific cytoskeletal marker, and S100B, a neurotrophin that when present at high concentrations becomes neurotoxic $[6,28,29]$. Results obtained from both immunofluorescence and Western blot analysis showed a significantly higher GFAP immunoreactivity in primary $3 \times$ Tg-AD astrocytes than non-Tg cells (immunofluorescence: $P<0.05$; Western blot $P<0.01$ ) (Figures 2(a), 2(b), 2(e), and 2(f)), while we did not detect changes in S100B signal $(P>0.05)$ (Figures 2(c), 2(d), 2(e), and 2(g)).

A neuroinflammatory environment is mainly characterized by the production and activation of two inducible enzymes: the prostanoid-generating enzyme COX-2 and iNOS [15]. Here, we tested the expression of these two enzymes in non-Tg and $3 \times \mathrm{Tg}-\mathrm{AD}$ primary astrocytes. Results showed that iNOS expression is significantly higher in transgenic-derived primary astrocytes than non-Tg cells $(P<0.01)$ (Figures 2(e) and 2(h)). We did not find any statistical difference in COX-2 expression between the two experimental groups $(P>0.05)$ (Figures 2(e) and 2(i)).

Collectively, these results show that reactive astrogliosis is detectable in mature $3 \times \mathrm{Tg}-\mathrm{AD}$ cortical astrocytes.

3.2. PEA Improves Neuronal Viability and Counteracts Reactive Astrogliosis In Vitro. To test whether PEA treatment could have any toxic effect on astrocyte and neuronal viability, we performed the neutral red assay. Results showed that PEA did not affect astrocytes or neuronal viability at all concentrations tested $(P>0.05)$ (Figures 3(a) and $3(\mathrm{~b}))$. Surprisingly, the highest PEA concentration significantly improved neuronal viability $(+5.35 \% ; P<0.001)$ (Figure 3(b)).

Next, we tested the ability of PEA, at different concentrations $(0.01,0.1$, and $1 \mu \mathrm{M})$, to counteract reactive astrogliosis. Western blot analyses showed that PEA treatment prevented GFAP increase in primary astrocytes derived from newborn $3 \times \mathrm{Tg}$-AD mice in a concentration-dependent manner $(P<0.05)$ (Figures 3(c) and 3(d)). Results by immunofluorescence confirmed this trend, although only the highest dose of PEA reached statistical significance $(P<0.05)$ (Figures 3(f) and 3(g)). Moreover, by Western blot, we found that $1 \mu \mathrm{M}$ PEA was able to significantly reduce iNOS expression $(P<0.05)$ (Figures 3(c) and 3(e)).

These results show that PEA has no toxicity in both astrocytes and neurons from $3 \times \mathrm{Tg}-\mathrm{AD}$ mice, at the concentrations tested; rather, it promotes neuron viability. Moreover, PEA counteracts reactive astrogliosis in mature $3 \times \mathrm{Tg}-\mathrm{AD}$ primary astrocytes.

3.3. Chronic Um-PEA Normalizes Reactive Astrogliosis in the Frontal Cortex of $3 \times T g-A D$ Mice. Given the interesting in vitro results, and with the aim of further exploring PEA effectiveness in the triple transgenic model of $\mathrm{AD}$, we decided to translate the study in vivo. Specifically, we tested the effect of chronic um-PEA treatment on reactive astrogliosis and neuronal functionality in FCs of 6-monthold $3 \times \mathrm{Tg}$-AD mice, compared to their age-matched nonTg littermates.
Confirming our in vitro observations, we found astrocyte activation in $\mathrm{FC}$ of $3 \times \mathrm{Tg}-\mathrm{AD}$ mice when compared with their age-matched non-Tg littermates. Indeed, we found, by RTPCR and Western blot, an increase of both GFAP and $\mathrm{S} 100 \mathrm{~B}$ expression in placebo-treated $3 \times \mathrm{Tg}-\mathrm{AD}$ mice in comparison with placebo-treated non-Tg mice $(P<0.05)$ (Figures 4(a), 4(b), 4(c), 4(f), 4(g), and 4(h)). Um-PEA chronic treatment greatly controlled such astrocytic activation, significantly decreasing GFAP mRNA and protein expression $(P<0.05)$ (Figures 4(a), 4(b), 4(f), and 4(g)). Moreover, the two-way ANOVA showed a significant genotype-by-treatment interaction effect on GFAP transcription $\left(F_{\text {genotypextreatment }(1,23)}=7.872, P=0.0062\right)($ Figure $4(\mathrm{~g}))$ and expression ( $\left.F_{\text {genotypextreatment }(1,23)}=4.829, P=0.0337\right)$ (Figure $4(\mathrm{~g})$ ). Surprisingly, um-PEA also induced a trend toward a decrease $(-20 \%)$ of S100B protein expression in $3 \times \mathrm{Tg}-\mathrm{AD}$ mice compared to placebo-treated $3 \times \mathrm{Tg}-\mathrm{AD}$ ones (Figures 4(a), 4(c), 4(f), and 4(h)).

Regarding the parameters related to the inflammatory process, RT-PCR and Western blot results showed a significant increase of iNOS transcription $(P<0.001)$ (Figures $4(\mathrm{a})$ and $4(\mathrm{~d}))$ and expression $(P<0.05)$ (Figures $4(\mathrm{f})$ and $4(\mathrm{i})$ ) in the $\mathrm{FC}$ of placebo-treated $3 \times \mathrm{Tg}-\mathrm{AD}$ mice in comparison with placebo-treated non- $\mathrm{Tg}$ animals. Interestingly, chronic um-PEA treatment greatly controlled the induced production of this proinflammatory enzyme (RT-PCR: $P<0.001$; Western blot: $P<0.05$ ) (Figures 4(a), 4(d), 4(f), and 4(i)). In addition, two-way ANOVA showed a significant genotype-by-treatment interaction effect in iNOS transcription $\left(F_{\text {genotypextreatment }(1,23)}=28.37, P<0.0001\right)$ (Figure $\left.4(\mathrm{~d})\right)$ and protein expression ( $F_{\text {genotypextreatment }(1,23)}=4.894, P=$ 0.0306 ) (Figure $4(\mathrm{i})$ ). As in in vitro results, neither genotype nor treatment induced changes in COX-2 transcript and protein expression (Figures 4(a), 4(e), 4(f), and 4(j)).

Interestingly, using Western blot experiments, we found a trend toward an increase of $\mathrm{A} \beta_{(1-42)}(+20 \%)$ in the FCs of transgenic mice in comparison with the nonTg animals. This trend, which follows the observed changes in parameters related to astrocyte activation and neuroinflammation, is in line with the evidence available in literature indicating that 6 -month-old $3 \times \mathrm{Tg}-\mathrm{AD}$ mice show $\mathrm{A} \beta$ overexpression predominantly in FC layers 4 to 5 [23]. Moreover, chronic um-PEA treatment dampened the expression of $\mathrm{A} \beta$ in $3 \times \mathrm{Tg}-\mathrm{AD}$ mice, although this failed to reach significance $(-34.23 \%$ ) (Figures 4 (f) and $4(\mathrm{k}))$. Despite this evidence, further experiments will be required to demonstrate the existence of a causative correlation between the reduction of $\mathrm{A} \beta$ load and the control of neuroinflammation.

Combined, our results demonstrate the presence of activated astrocytes and a proinflammatory environment in the FCs of $3 \times \mathrm{Tg}-\mathrm{AD}$ mice at 6 months of age. Additionally, we show that chronic um-PEA treatment efficaciously controls these alterations in the $\mathrm{AD}$ brain.

3.4. Chronic um-PEA Normalizes Astrocyte Support to Neuronal Functionality in the Frontal Cortex of $3 \times T g-A D$ Mice. Finally, we wanted to explore if there was any impairment in neuronal functionality guided by astrocytes 

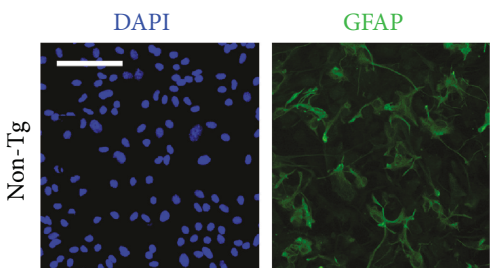

DAPI/GFAP
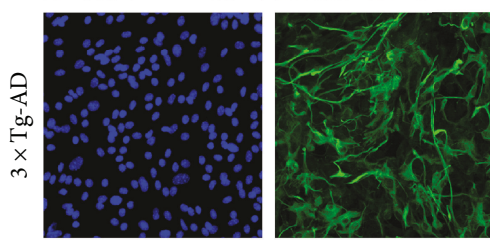

(a)
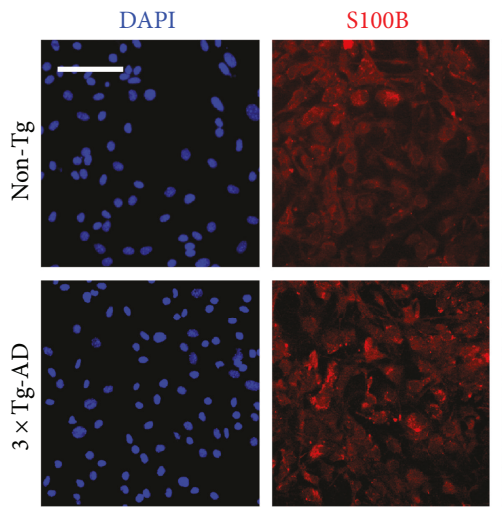

DAPI/S100B
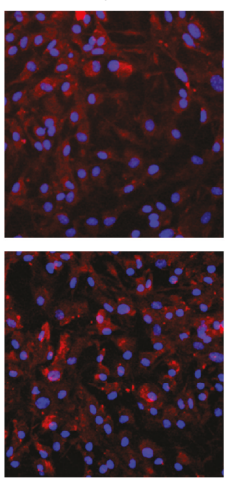

(c)

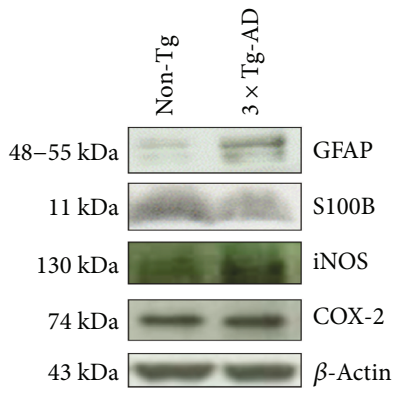

(e)

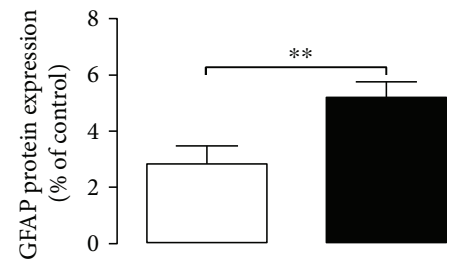

(f)

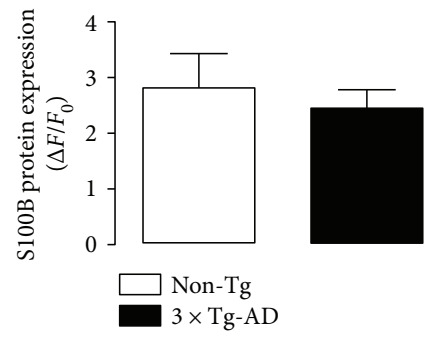

(d)

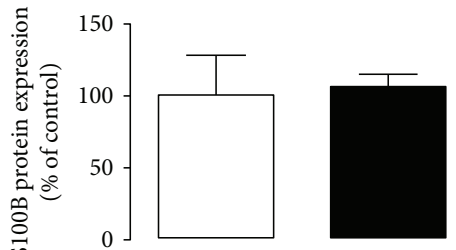

(g)

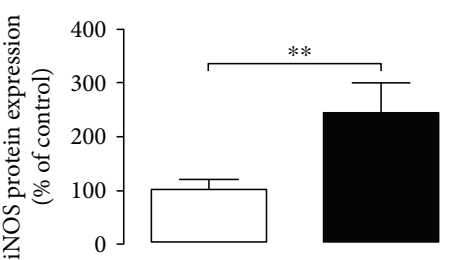

(h)

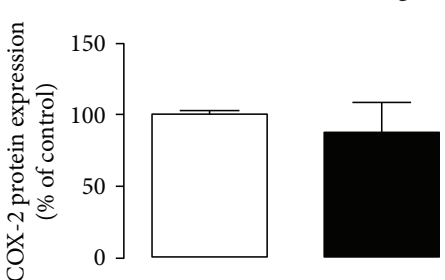

(i)

FIgURE 2: Study of parameters related to reactive astrogliosis in $3 \times \mathrm{Tg}-\mathrm{AD}$ and non-Tg primary astrocytes. (a) Representative fluorescent photomicrographs of GFAP (green) and (b) signal quantification in both non-Tg (white bar) and $3 \times \mathrm{Tg}-\mathrm{AD}$ (black bar) primary astrocytes. (c) Representative fluorescent photomicrographs of S100B (red) and (d) signal quantification in both non-Tg (white bar) and $3 \times \mathrm{Tg}-\mathrm{AD}$ (black bar) primary astrocytes. Nuclei were stained with DAPI (blue). Scale bar is $50 \mu \mathrm{m}$. Fluorescence analysis is expressed as $\Delta F / F_{0}$. (e) Representative bands and Western blot densitometric analysis of (f) GFAP, (g) S100B, (h) iNOS, and (i) COX-2. $\beta$-Actin was used as loading control. Results are expressed as percentage of the mean control value (non-Tg cells). Experiments were performed three times in triplicate. Data are presented as mean \pm SEM. The statistical analysis was performed by Student's $t$-test $\left({ }^{*} P<0.05\right.$ and ${ }^{* *} P<0.01$ versus non-Tg group). 


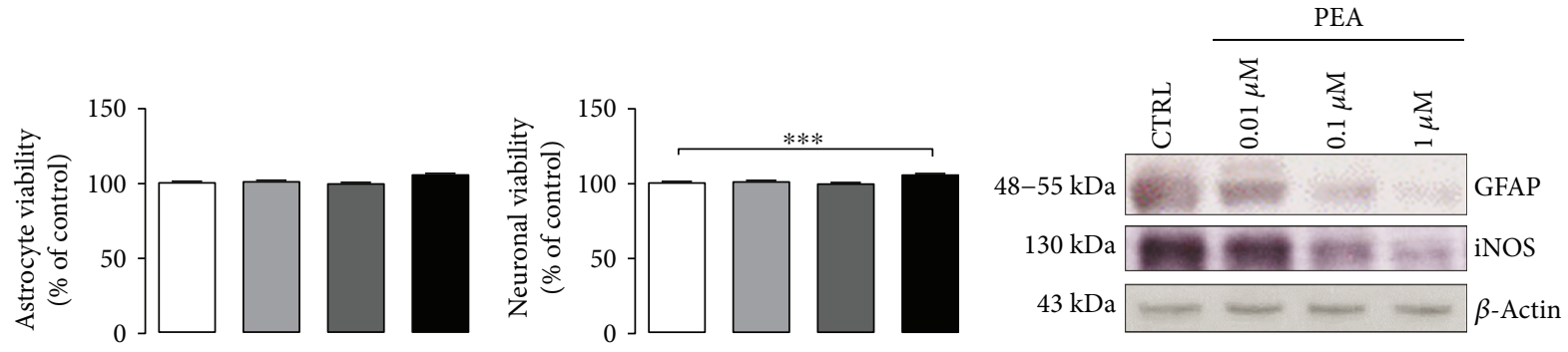

(a)

(b)

(c)

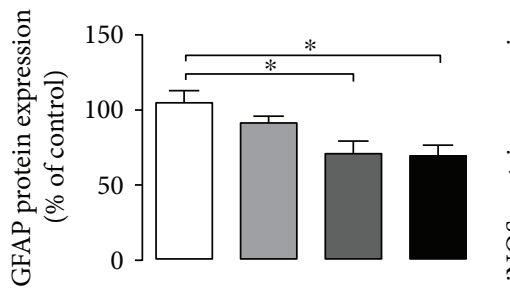

(d)

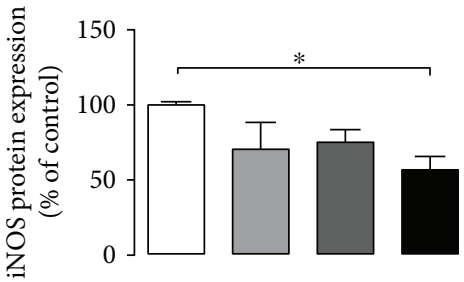

(e)

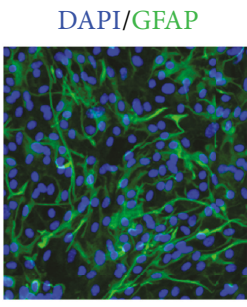

GFAP

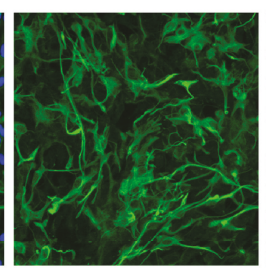

DAPI
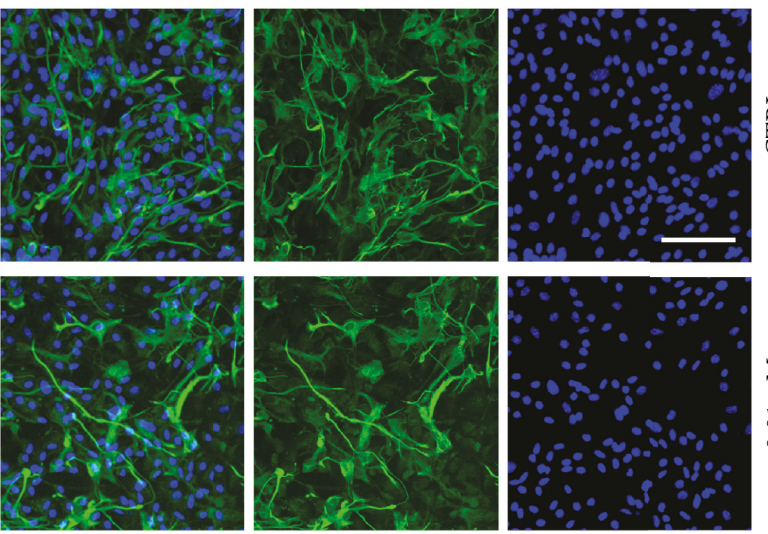

곱
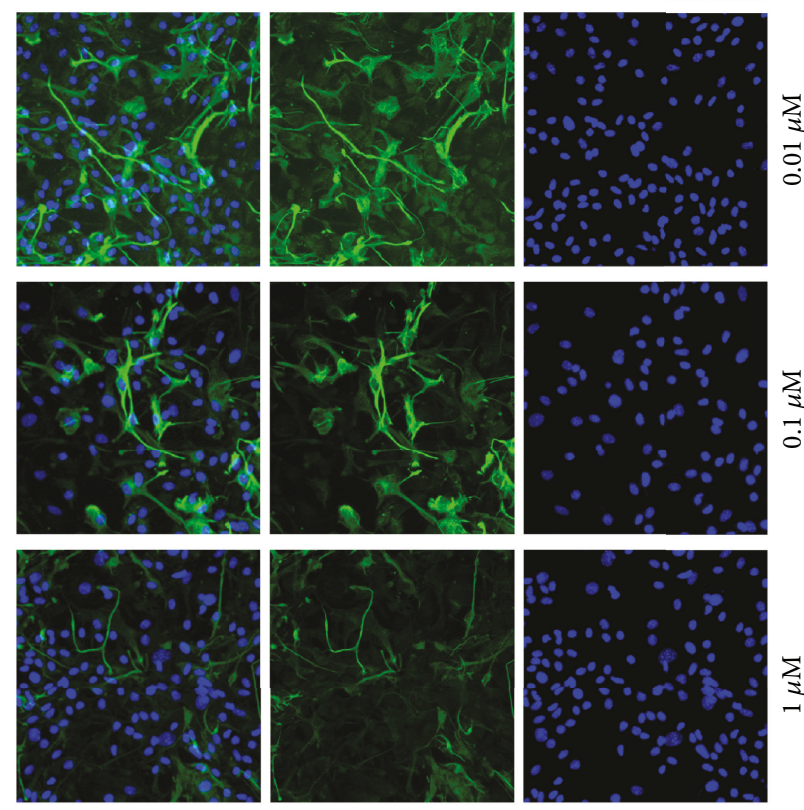

(f)

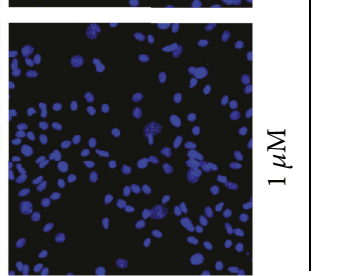

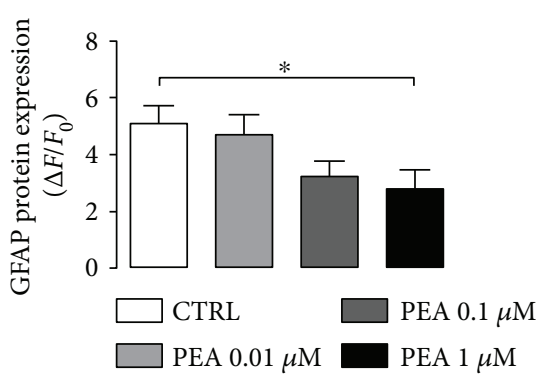

(g)

FIGURE 3: Effect of PEA treatment on astrocyte and neuronal viability and reactive astrogliosis in $3 \times \mathrm{Tg}$-AD cells. Evaluation of (a) astrocyte and (b) neuronal viability tested by neutral red uptake assay after $24 \mathrm{~h}$ PEA treatment $(0.01-0.1-1 \mu \mathrm{M})$. (c) Representative immunoreactive signals and Western blot densitometric analysis of (d) GFAP and (e) iNOS. $\beta$-Actin was used as loading control. Results are expressed as percentage of the mean control value (CTRL). (f) Representative fluorescent photomicrographs of GFAP (green) staining in $3 \times \mathrm{Tg}-\mathrm{AD}$ primary astrocytes. Nuclei were stained with DAPI (blue). Scale bar is $50 \mu \mathrm{m}$. (g) Fluorescence analysis is expressed as $\Delta F / F_{0}$. Experiments were performed three times in triplicate. Data are presented as mean \pm SEM. The statistical analysis was performed by one-way ANOVA followed by Bonferroni's post hoc multiple comparison test $\left({ }^{*} P<0.05\right.$ and ${ }^{* * *} P<0.001$ versus CTRL group). 


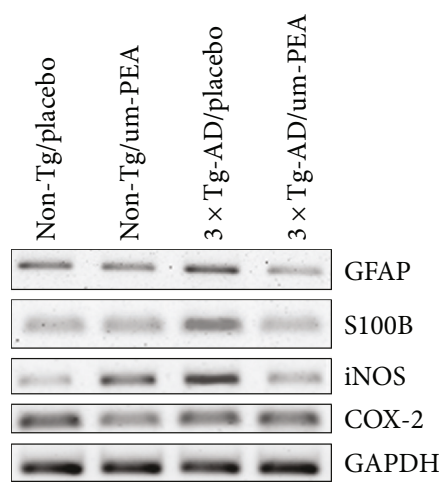

(a)

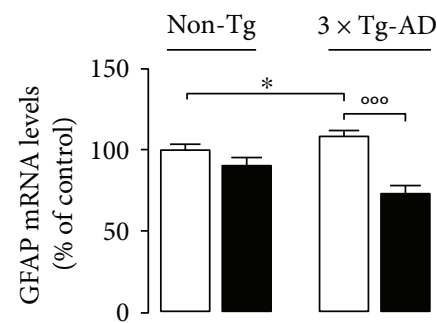

(b)

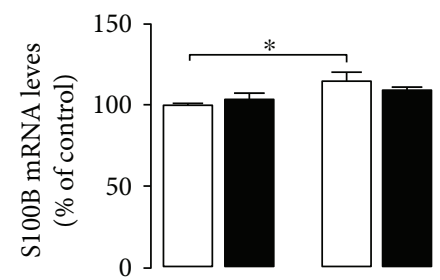

(c)

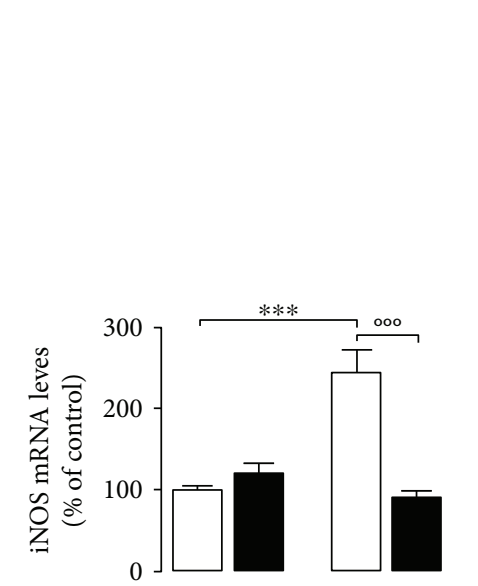

(d)

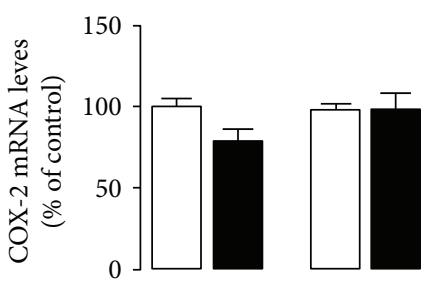

(e)

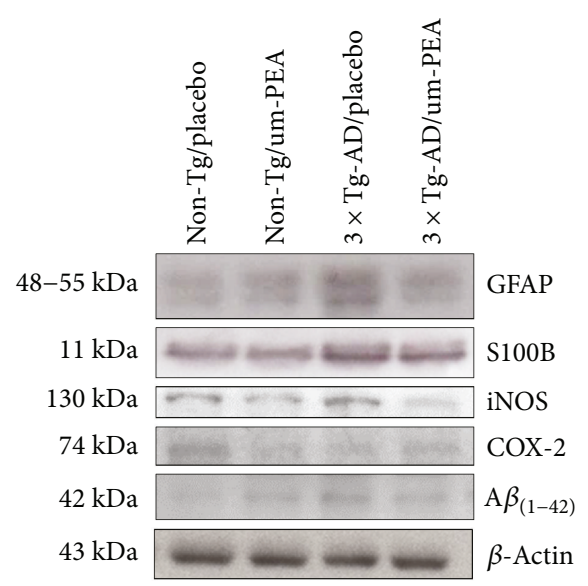

(f)

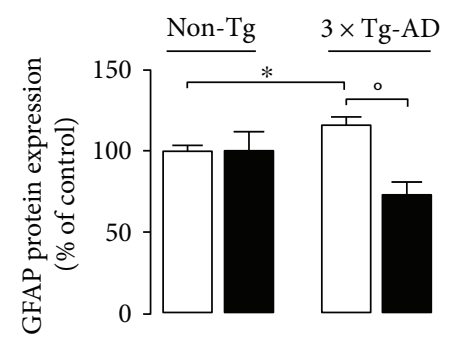

(g)

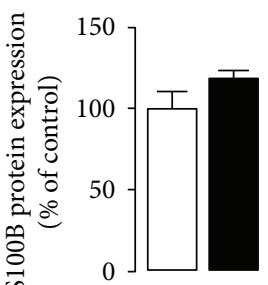

(h)
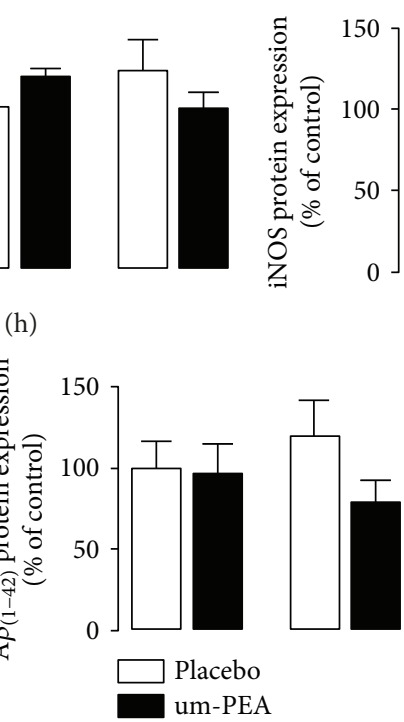

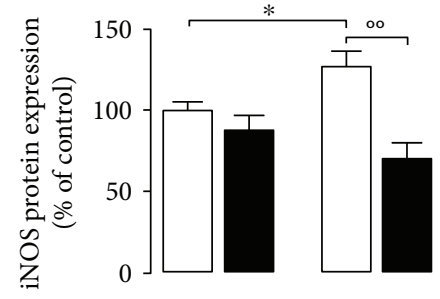

(i) (j)

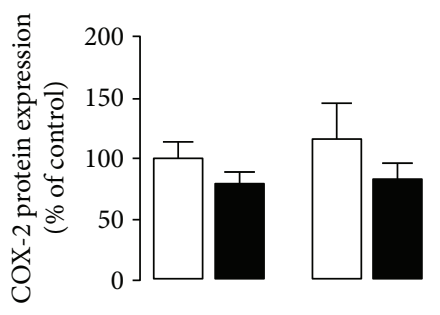

(k)

FIgURE 4: Effect of chronic um-PEA on reactive astrogliosis and $\mathrm{A} \beta_{(1-42)}$ expression in the $\mathrm{FC}$ of $3 \times \mathrm{Tg}-\mathrm{AD}$ and non-Tg mice. (a) Representative bands from RT-PCR performed in FC homogenates for GFAP, S100B, iNOS, and COX-2, and (b-e) densitometric analysis of the corresponding signals normalized to GAPDH. (f) Representative immunoreactive species and Western blot densitometric analysis of (g) GFAP, (h) S100B, (i) COX-2, (j) iNOS, and (k) A $\beta_{(1-42)}$. $\beta$-Actin was used as loading control. Results are expressed as percentage of the mean control value (non-Tg/placebo). Experiments were performed three times in triplicate. Data are presented as mean \pm SEM. The statistical analysis was performed by two-way ANOVA followed by Bonferroni's post hoc multiple comparison test $\left({ }^{*} P<0.05\right.$ and ${ }^{* * *} \mathrm{P}<0.001$ versus non-Tg/placebo group; ${ }^{\circ} \mathrm{P}<0.05,{ }^{\circ} \mathrm{P}<0.01$, and ${ }^{\circ{ }^{\circ 0} \mathrm{P}}<0.001$ versus $3 \times \mathrm{Tg}$ - $\mathrm{AD} /$ placebo group). 


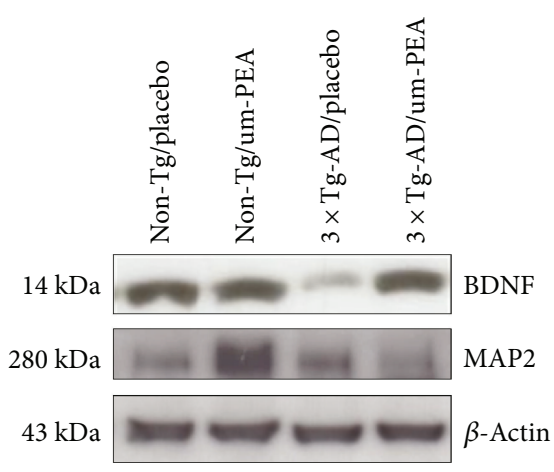

(a)

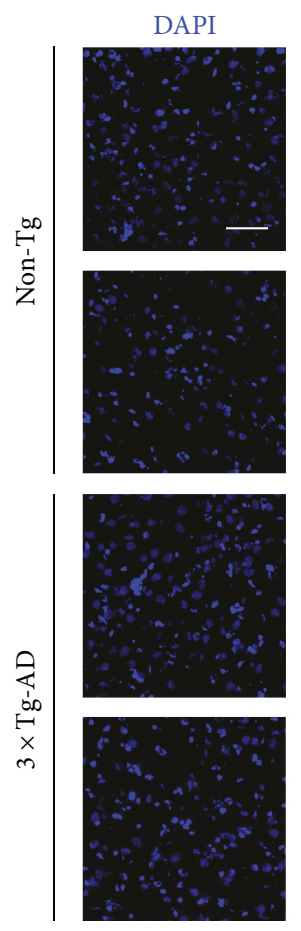

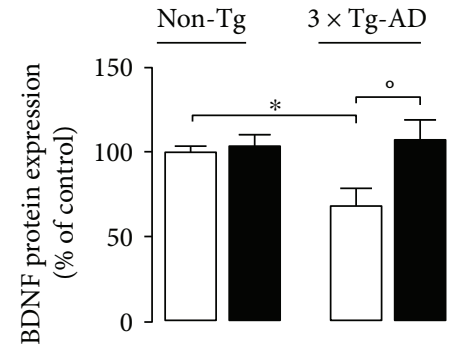

(b)
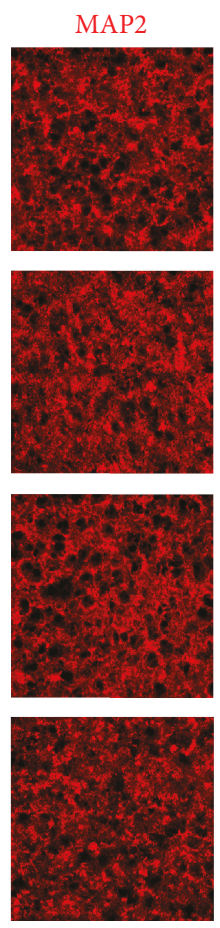

(d)

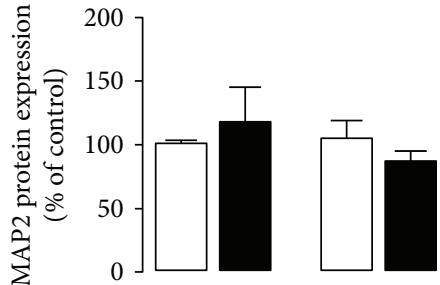

Placebo

um-PEA

(c)

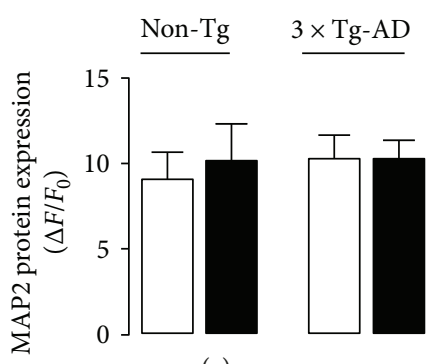

(e)

Figure 5: Effect of chronic um-PEA on neuronal support and survival in FC of $3 \times \mathrm{Tg}$-AD and non-Tg mice. (a) Representative immunoreactive species and Western blot densitometric analysis of (b) BDNF and (c) MAP2. $\beta$-Actin was used as loading control. Results are expressed as percentage of the mean control value (non-Tg/placebo). (d) Representative fluorescent photomicrographs of MAP2 (red) staining in FC of 6-month-old non-Tg and 3xTg-AD mice, placebo- or um-PEA-treated. Nuclei were stained with DAPI (blue). Scale bar is $50 \mu \mathrm{m}$. (e) Fluorescence analysis is expressed as $\Delta F / F_{0}$. Experiments were performed three times in triplicate. Data are presented as mean \pm SEM. The statistical analysis was performed by two-way ANOVA followed by Bonferroni's post hoc multiple comparison test $\left({ }^{*} \mathrm{P}<0.05\right.$ versus non-Tg/placebo group; ${ }^{\circ} \mathrm{P}<0.05$ versus $3 \times \mathrm{Tg}-\mathrm{AD} /$ placebo group).

that is responsible for BDNF production [30]. To address this goal, we tested both BDNF and MAP2 expression. Western blot analysis showed an impaired production of BDNF in the FC of placebo-treated $3 \times \mathrm{Tg}-\mathrm{AD}$ animals compared to placebo-treated non-Tg littermates. Interestingly, um-PEA significantly counteracted such decrease $(P<0.05)$ (Figures 5(a) and 5(b)). Surprisingly, these modifications did not affect neuronal survival. Indeed, by both Western blot and immunofluorescence, we did not observe modifications in MAP2 expression in placebo-treated transgenic mice in comparison with placebo-treated non-Tg animals (Figures 5(a), 5(c), 5(d), and 5(e)).

Altogether, these results demonstrate the presence of reduced trophic support to FC neurons in 6-month-old $3 \times \mathrm{Tg}-\mathrm{AD}$ mice; this has not yet impaired neuronal viability. Chronic um-PEA treatment restores the neuronal trophic support. 


\section{Discussion}

Astrocytes represent the crucial element of a defensive system of CNS. Cerebral insults trigger reactive astrogliosis, which represents a conserved defensive reprogramming of astroglial cells. It is a very heterogeneous phenomenon that limits damage and facilitates postlesion regeneration of neural networks [31-33], although it may become neurotoxic in some circumstances [34]. In fact, astrogliosis involves complex biochemical and functional remodelling and produces multiple reactive cellular phenotypes. The common feature of pathological astroglial change is the morphological cellular remodelling towards atrophy or hypertrophy $[35,36]$. This sometimes occurs at early pathological stages preceding (and possibly precipitating) neuronal death. Such an early activation is observed in $\mathrm{AD}$, when astrocytes, in proximity of plaques and $\beta$-amyloid deposits, acquire a reactive phenotype detectable by an increased expression of intermediate filaments and overproduction of proinflammatory mediators $[23,35,37]$. By this way, astrocytes contribute to neurodegeneration, becoming interesting targets for the development of innovative therapies [38-41]. Here, we provide the first in vitro evidence of the presence of a basal reactive state in primary astrocytes derived from $3 \times \mathrm{Tg}$ - $\mathrm{AD}$ mice cortices, as well as of the capability of PEA to counteract such a phenomenon and improve neuronal viability. We also obtained important data on the beneficial pharmacological properties of this compound by testing the effect of a chronic treatment with um-PEA in $3 \times \mathrm{Tg}-\mathrm{AD}$ mice. Our in vivo results indicate that, during the mild stage of the disease, both reactive astrogliosis and neuroinflammation are already detectable in the FCs of transgenic animals, and that chronic um-PEA is able to alleviate both indices.

Several clinical studies have shown that an impairment of hippocampus, entorhinal cortex, posterior cingulate gyrus, amygdala, and parahippocampal gyrus occur in early $\mathrm{AD}[42-45]$. When $\mathrm{AD}$ becomes severe, atrophy progresses from the hippocampus to the FC [46]. Interestingly, our results revealed the absence of neuronal atrophy in 6-month-old $3 \times \mathrm{Tg}-\mathrm{AD}$ mice (age that corresponds to a mild stage of pathology), but detected the early presence of reactive astrogliosis, confirming that such phenomenon is precocious and comes before neuronal loss in this animal model.

Since glial cells, previously considered only space-filling support cells of the CNS, are indeed highly involved in the maintenance of CNS homeostasis, we wondered whether cells in the FC were abnormally activated during the mild stage of the disease, before atrophy occurs. To this aim, we first performed an in vitro screening of $3 \times \mathrm{Tg}-\mathrm{AD}$ cortical astrocytes and compared them with non-Tg-derived cells, for signs of astrocyte activation and inflammation. In the absence of any exogenous insult, $3 \times \mathrm{Tg}-\mathrm{AD}$ primary astrocytes showed a basal reactive and proinflammatory phenotype, as demonstrated by the increased expression of GFAP and iNOS, a cytoskeletal astrocyte marker and a proinflammatory inducible enzyme, respectively. Since reactive gliosis may occur before plaque formation, these results suggest that astrocytes can contribute to $\mathrm{AD}$ progression before the development of the main AD hallmarks [40]. Since some astrocytes express little or no GFAP [47], we used an additional astrocytic marker, such as $\mathrm{S} 100 \mathrm{~B}$, a $\mathrm{Ca}^{2+}$-binding protein. S100B is a neurotrophic factor that improves neuronal survival during CNS development [48]. In adulthood, levels of S100B increase after brain damage and can be neurotoxic and proinflammatory [49]. We did not find any genotypic difference in S100B expression, in our experimental condition. Therefore, it is possible that this protein maintains trophic functionality in the cell population analysed in the absence of an actual injury. Moreover, to further evaluate the inflammatory component in this animal model, we studied a proinflammatory enzyme, COX-2, responsible for prostanoid formation. Its involvement in the cascade of events leading to neurodegeneration in $\mathrm{AD}$ is still controversial [50]. COX-2 expression did not change in $3 \times \mathrm{Tg}-\mathrm{AD}$ cortical astrocytes, confirming the hypothesis that COX-2 induction could be connected with neurotoxicity [51], but this was not assessed in this in vitro study.

In the last few years, increasing evidence has confirmed the effectiveness of PEA treatment against inflammation in different models of neurodegeneration $[15,21,52,53]$. Here, we tested the effectiveness of this compound on those parameters that we found to be influenced by the $3 \times \mathrm{Tg}-\mathrm{AD}$ genotype. Therefore, first we demonstrated the absence of astrocytic and neuronal toxicity of PEA at three different concentrations $(0.01,0.1$, and $1 \mu \mathrm{M})$. Then, we performed the neutral red assay, a viability test, in both primary astrocytes and primary neurons, confirming that PEA is not cytotoxic and fosters neuronal viability at the highest concentration investigated. This result agrees with the already proven neuroprotective effects of PEA in different preclinical models of neurological disorders $[15,54,55]$. In a surgical rat model of $\mathrm{AD}$, we recently demonstrated the ability of PEA to counteract the reactive gliosis caused by $\mathrm{A} \beta_{(1-42)}$ hippocampal infusion [15]. Here, we demonstrated that PEA exerts this pharmacological effect in a transgenic model of $\mathrm{AD}$, expanding the range of pathological targets treatable with this compound. In fact, the present in vivo experiments confirmed the therapeutic potential of chronic PEA administration. Moreover, such experiments were designed to simulate a clinic-like treatment schedule; for this reason, 3 -month-old $3 \times \mathrm{Tg}-\mathrm{AD}$ and sex- and age-matched non$\mathrm{Tg}$ animals were chronically treated for three months with placebo or um-PEA, a crystalline form on micrometric size, which improves its pharmacokinetics properties [24, 56]. Consistent with our in vitro observations, in the FC of $3 \times \mathrm{Tg}-\mathrm{AD}$ mice, we detected the presence of reactive gliosis in the mild stage of the disease, as shown by the increased transcription and expression of both GFAP and iNOS. The expression of both S100B and COX-2 were not affected by the genotype. Only S100B mRNA was increased in transgenic cortices. Interestingly, chronic um-PEA treatment dampened such alterations, confirming its effectiveness against reactive gliosis in vivo. Another interesting result was the detection of lower levels of BDNF in the FC of transgenic mice in comparison with non-Tg littermates, and, even more significant, the discovery of the ability of chronic um-PEA at increasing the expression of BDNF. Despite the fact that we found a 
decreased expression of BDNF together with the presence of reactive gliosis, known to be able to amplify CNS damages $[14,47]$, we did not detect any impairment of neuronal viability in FC of $3 \times \mathrm{Tg}-\mathrm{AD}$ mice. Such evidence was surprising because it is widely accepted that at 6 months of age these transgenic mice show early symptoms of AD-like pathology and behavioural alterations [23, 57-59]. However, since CNS impairment in AD travels broadly from hippocampus to FC, we can speculate that the massive alteration of this brain region has not occurred as yet, and neurons can somehow survive these insults. In fact, Castello and colleagues demonstrated that BDNF reduction does not exacerbate $\mathrm{A} \beta$ and tau pathology, but is a consequence of the pathology itself [60]. If this is true, the improvement in BDNF production that we found in mice after chronic um-PEA treatment can be a positive sign of the control that such a molecule has on the pathology in its entirety, and not only against reactive gliosis.

\section{Conclusions}

In the present study, we expand the knowledge on glial activity in a triple transgenic model of $\mathrm{AD}$ that closely mimics the main features of the pathology. Here, we provide the first evidence that $3 \times \mathrm{Tg}$ - $\mathrm{AD}$ mice present signs of reactive gliosis in the FC at an early stage of the disease. Moreover, we demonstrate for the first time that acute PEA in vitro, as well as chronic um-PEA in vivo, may counteract such phenomenon, improving the trophic support to neurons, in absence of astrocytes and neuronal toxicity. By the virtue of its safety [61], and considering the growing body of evidence regarding its efficacy, we foresee a possible translation of the results collected in animal models into the clinical practice, in the near future.

\section{Conflicts of Interest}

The authors report no financial interests or potential conflicts of interest.

\section{Acknowledgments}

This research was supported by the Italian Ministry of Education, University and Research (MIUR) to Luca Steardo (PON01-02512 and PRIN Protocol 2009NKZCNX) and Sapienza University of Rome to Caterina Scuderi (Protocol C26A15X58E) and Maria Rosanna Bronzuoli (Protocol C26N15BHZZ).

\section{References}

[1] R. Anand, K. D. Gill, and A. A. Mahdi, "Therapeutics of Alzheimer's disease: past, present and future," Neuropharmacology, vol. 76, pp. 27-50, 2014.

[2] H. Braak and E. Braak, "Neuropil threads occur in dendrites of tangle-bearing nerve cells," Neuropathology and Applied Neurobiology, vol. 14, no. 1, pp. 39-44, 1988.

[3] P. Merz, H. Wisniewski, R. Somerville, S. A. Bobin, C. L. Masters, and K. Iqbal, "Ultrastructural morphology of amyloid fibrils from neuritic and amyloid plaques," Acta Neuropathology, vol. 60, no. 1-2, pp. 113-124, 1983.

[4] J. J. Rodríguez, M. Olabarria, A. Chvatal, and A. Verkhratsky, "Astroglia in dementia and Alzheimer's disease," Cell Death of Differentiation, vol. 16, no. 3, pp. 378-385, 2009.

[5] H. Akiyama, S. Barger, S. Barnum, B. Bradt, J. Bauer, and G. M. Cole, "Inflammation and Alzheimer's disease," Neurobiology of Aging, vol. 21, no. 3, pp. 383-421, 2000.

[6] A. Verkhratsky, M. Olabarria, H. N. Noristani, C. Y. Yeh, and J. J. Rodriguez, “Astrocytes in Alzheimer's disease," Neurotherapeutics, vol. 7, no. 4, pp. 399-412, 2010.

[7] A. Verkhratsky, M. V. Sofroniew, A. Messing et al., "Neurological diseases as primary gliopathies: a reassessment of neurocentrism," ASN Neuro, vol. 4, no. 3, article AN20120010, 2012.

[8] Z. Yang and K. K. W. Wang, "Glial fibrillary acidic protein: from intermediate filament assembly and gliosis to neurobiomarker," Trends in Neurosciences, vol. 38, no. 6, pp. 364-374, 2015.

[9] G. Esposito, C. Scuderi, J. Lu, C. Savani, D. De Filippis, and T. Iuvone, "S100B induces tau protein hyperphosphorylation via Dickopff-1 up-regulation and disrupts the Wnt pathway in human neural stem cells," Journal of Cellular and Molecular Medicine, vol. 12, no. 3, pp. 914-927, 2008.

[10] L. J. van Eldik and M. S. Wainwright, "The Janus face of glial-derived S100B: beneficial and detrimental functions in the brain," Restorative Neurology and Neuroscience, vol. 21, no. 3-4, pp. 97-108, 2003.

[11] C. Lindberg, E. Hjorth, C. Post, B. Winblad, and M. Schultzberg, "Cytokine production by a human microglial cell line: effects of ßamyloid and $\alpha$-melanocyte-stimulating hormone," Neurotoxicity Research, vol. 8, no. 3-4, pp. 267276, 2005.

[12] G. C. Brown and A. Bal-Price, "Inflammatory neurodegeneration mediated by nitric oxide, glutamate, and mitochondria," Molecular Neurobiology, vol. 27, no. 3, pp. 325-355, 2003.

[13] J. E. Burda and M. V. Sofroniew, "Reactive gliosis and the multicellular response to CNS damage and disease," Neuron, vol. 81, no. 2, pp. 229-248, 2014.

[14] L. Steardo Jr., M. R. Bronzuoli, A. Iacomino, G. Esposito, L. Steardo, and C. Scuderi, "Does neuroinflammation turn on the flame in Alzheimer's disease? Focus on astrocytes," Frontiers in Neuroscience, vol. 9, p. 259, 2015.

[15] C. Scuderi, C. Stecca, M. Valenza et al., "Palmitoylethanolamide controls reactive gliosis and exerts neuroprotective functions in a rat model of Alzheimer's disease," Cell Death \& Disease, vol. 5, no. 9, article e1419, 2014.

[16] S. E. O'Bryant, V. Hobson, J. R. Hall et al., "Brain-derived neurotrophic factor levels in Alzheimer's disease," Journal of Alzheimer's Disease, vol. 17, no. 2, pp. 337-341, 2009.

[17] A. N. Voineskos, J. P. Lerch, D. Felsky, S. Shaikh, T. K. Rajji, and D. Miranda, "The brain-derived neurotrophic factor Val66Met polymorphism and prediction of neural risk for Alzheimer disease," Archives of General Psychiatry, vol. 68, no. 2, pp. 198-206, 2011.

[18] V. K. Sandhya, R. Raju, R. Verma et al., "A network map of BDNF/TRKB and BDNF/p75NTR signaling system," Journal of Cell Communication and Signaling, vol. 7, no. 4, pp. 301307, 2013.

[19] C. Scuderi, G. Esposito, A. Blasio, M. Valenza, P. Arietti, and L. Steardo Jr., "Palmitoylethanolamide counteracts reactive astrogliosis induced by $\beta$-amyloid peptide," Journal of 
Cellular and Molecular Medicine, vol. 15, no. 12, pp. 26642674, 2011.

[20] C. Scuderi, M. Valenza, C. Stecca, G. Esposito, M. R. Carratù, and L. Steardo, "Palmitoylethanolamide exerts neuroprotective effects in mixed neuroglial cultures and organotypic hippocampal slices via peroxisome proliferator-activated receptor- $\alpha$," Journal of Neuroinflammation, vol. 9, no. 1, 2012.

[21] G. D'Agostino, R. Russo, C. Avagliano, C. Cristiano, R. Meli, and A. Calignano, "Palmitoylethanolamide protects against the amyloid- $\beta 25$-35-induced learning and memory impairment in mice, an experimental model of Alzheimer disease," Neuropsychopharmacology, vol. 37, no. 7, pp. 17841792, 2012.

[22] M. C. Tomasini, A. C. Borelli, S. Beggiato, L. Ferraro, T. Cassano, and S. Tanganelli, "Differential effects of palmitoylethanolamide against amyloid- $\beta$ induced toxicity in cortical neuronal and astrocytic primary cultures from wild-type and 3xTg-AD mice," Journal of Alzheimer's Disease, vol. 46, no. 2, pp. 407-421, 2015.

[23] S. Oddo, A. Caccamo, J. D. Shepherd et al., "Triple-transgenic model of Alzheimer's disease with plaques and tangles: intracellular A $\beta$ and synaptic dysfunction," Neuron, vol. 39, no. 3, pp. 409-421, 2003.

[24] S. Petrosino and V. Di Marzo, "The pharmacology of palmitoylethanolamide and first data on the therapeutic efficacy of some of its new formulations," British Journal of Pharmacology, vol. 174, no. 11, pp. 1349-1365, 2017.

[25] B. Costa, S. Conti, G. Giagnoni, and M. Colleoni, "Therapeutic effect of the endogenous fatty acid amide, palmitoylethanolamide, in rat acute inflammation: inhibition of nitric oxide and cyclo-oxygenase systems," British Journal of Pharmacology, vol. 137, no. 4, pp. 413-420, 2002.

[26] S. L. Grillo, J. Keereetaweep, M. A. Grillo, K. D. Chapman, and P. Koulen, "N-Palmitoylethanolamine depot injection increased its tissue levels and those of other acylethanolamide lipids," Drug Design, Development and Therapy, vol. 7, pp. 747-752, 2013.

[27] C. Scuderi, C. Stecca, M. R. Bronzuoli et al., "Sirtuin modulators control reactive gliosis in an in vitro model of Alzheimer's disease," Frontiers in Pharmacology, vol. 5, p. 89, 2014.

[28] J. Baudier, C. Delphin, D. Grunwald, S. Khochbin, and J. J. Lawrence, "Characterization of the tumor suppressor protein p53 as a protein kinase C substrate and a S100b-binding protein," Proceedings of the National Academy of Sciences of the United States of America, vol. 89, no. 23, pp. 11627$11631,1992$.

[29] C. Scotto, J. C. Deloulme, D. Rousseau, E. Chambaz, and J. Baudier, "Calcium and S100B regulation of p53-dependent cell growth arrest and apoptosis," Molecular and Cellular Biology, vol. 18, no. 7, pp. 4272-4281, 1998.

[30] Y. Sato, Y. Chin, T. Kato et al., "White matter activated glial cells produce BDNF in a stroke model of monkeys," Neuroscience Research, vol. 65, no. 1, pp. 71-78, 2009.

[31] V. Parpura, M. T. Heneka, V. Montana et al., "Glial cells in (patho)physiology," Journal of Neurochemistry, vol. 121, no. 1, pp. 4-27, 2012.

[32] A. Verkhratsky, R. Zorec, J. J. Rodríguez, and V. Parpura, "Astroglia dynamics in ageing and Alzheimer's disease," Current Opinion in Pharmacology, vol. 26, pp. 74-79, 2016.

[33] M. Pekny and M. Pekna, "Reactive gliosis in the pathogenesis of CNS diseases," Biochimica et Biophysica Acta (BBA) -
Molecular Basis of Disease, vol. 1862, no. 3, pp. 483-491, 2016.

[34] S. A. Liddelow, K. A. Guttenplan, L. E. Clarke et al., "Neurotoxic reactive astrocytes are induced by activated microglia," Nature, vol. 541, no. 7638, pp. 481-487, 2017.

[35] M. Olabarria, H. N. Noristani, A. Verkhratsky, and J. J. Rodriguez, "Concomitant astroglial atrophy and astrogliosis in a triple transgenic animal model of Alzheimer's disease," Glia, vol. 58, no. 7, pp. 831-838, 2010.

[36] V. C. Jones, R. Atkinson-Dell, A. Verkhratsky, and L. Mohamet, "Aberrant iPSC-derived human astrocytes in Alzheimer's disease," Cell Death \& Disease, vol. 8, no. 3, article e2696, 2017.

[37] A. Verkhratsky, V. Parpura, M. Pekna, M. Pekny, and M. Sofroniew, "Glia in the pathogenesis of neurodegenerative diseases," Biochemical Society Transactions, vol. 42, no. 5, pp. 1291-1301, 2014.

[38] P. C. Chen, M. R. Vargas, A. K. Pani et al., "Nrf2-mediated neuroprotection in the MPTP mouse model of Parkinson's disease: critical role for the astrocyte," Proceedings of the National Academy of Sciences of the United States of America, vol. 106, no. 8, pp. 2933-2938, 2009.

[39] J. Bradford, J. Y. Shin, M. Roberts et al., "Mutant huntingtin in glial cells exacerbates neurological symptoms of Huntington disease mice," Journal of Biological Chemistry, vol. 285, no. 14, pp. 10653-10661, 2010.

[40] C. Acosta, H. D. Anderson, and C. M. Anderson, "Astrocyte dysfunction in Alzheimer disease," Journal of Neuroscience Research, vol. 95, no. 12, pp. 2430-2447, 2017.

[41] M. R. Bronzuoli, A. Iacomino, L. Steardo, and C. Scuderi, "Targeting neuroinflammation in Alzheimer's disease," Journal of Inflammation Research, vol. 9, pp. 199-208, 2016.

[42] M. Basso, J. Yang, L. Warren et al., "Volumetry of amygdala and hippocampus and memory performance in Alzheimer's disease," Psychiatry Research: Neuroimaging, vol. 146, no. 3, pp. 251-261, 2006.

[43] D. P. Devanand, G. Pradhaban, X. Liu et al., "Hippocampal and entorhinal atrophy in mild cognitive impairment: prediction of Alzheimer disease," Neurology, vol. 68, no. 11, pp. 828836, 2007.

[44] C. Pennanen, M. Kivipelto, S. Tuomainen et al., "Hippocampus and entorhinal cortex in mild cognitive impairment and early AD," Neurobiology of Aging, vol. 25, no. 3, pp. 303-310, 2004.

[45] H. Wolf, A. Hensel, F. Kruggel et al., "Structural correlates of mild cognitive impairment," Neurobiology of Aging, vol. 25, no. 7, pp. 913-924, 2004.

[46] R. I. Scahill, J. M. Schott, J. M. Stevens, M. N. Rossor, and N. C. Fox, "Mapping the evolution of regional atrophy in Alzheimer's disease: unbiased analysis of fluid-registered serial MRI," Proceedings of the National Academy of Sciences of the United States of America, vol. 99, no. 7, pp. 4703-4707, 2002.

[47] M. V. Sofroniew and H. V. Vinters, "Astrocytes: biology and pathology," Acta Neuropathologica, vol. 119, no. 1, pp. 7-35, 2010.

[48] A. Bhattacharyya, R. W. Oppenheim, D. Prevette, B. W. Moore, R. Brackenbury, and N. Ratner, "S100 is present in developing chicken neurons, and Schwann cells, and promotes neuron survival in vivo," Journal of Neurobiology, vol. 23, no. 4, pp. 451-466, 1992. 
[49] H. Zetterberg, D. H. Smith, and K. Blennow, "Biomarkers of mild traumatic brain injury in cerebrospinal fluid and blood," Nature Reviews Neurology, vol. 9, no. 4, pp. 201-210, 2013.

[50] L. Minghetti, "Cyclooxygenase-2 (COX-2) in inflammatory and degenerative brain diseases," Journal of Neuropathology and Experimental Neurology, vol. 63, no. 9, pp. 901-910, 2004.

[51] M. A. Meraz-Ríos, D. Toral-Rios, D. Franco-Bocanegra, J. Villeda-Hernández, and V. Campos-Peña, "Inflammatory process in Alzheimer's disease," Frontiers in Integrative Neuroscience, vol. 7, p. 59, 2013.

[52] E. Esposito, D. Impellizzeri, E. Mazzon, I. Paterniti, and S. Cuzzocrea, "Neuroprotective activities of palmitoylethanolamide in an animal model of Parkinson's disease," PLoS One, vol. 7, no. 8, article e41880, 2012.

[53] A. Rahimi, M. Faizi, F. Talebi, F. Noorbakhsh, F. Kahrizi, and N. Naderi, "Interaction between the protective effects of cannabidiol and palmitoylethanolamide in experimental model of multiple sclerosis in C57BL/6 mice," Neuroscience, vol. 290, pp. 279-287, 2015.

[54] S. D. Skaper, A. Buriani, R. Dal Toso et al., "The ALIAmide palmitoylethanolamide and cannabinoids, but not anandamide, are protective in a delayed postglutamate paradigm of excitotoxic death in cerebellar granule neurons," Proceedings of the National Academy of Sciences of the United States of America, vol. 93, no. 9, pp. 3984-3989, 1996.

[55] D. M. Lambert, S. Vandevoorde, G. Diependaele, S. J. Govaerts, and A. R. Robert, "Anticonvulsant activity of $N$ palmitoylethanolamide, a putative endocannabinoid, in mice," Epilepsia, vol. 42, no. 3, pp. 321-327, 2001.

[56] D. Impellizzeri, G. Bruschetta, M. Cordaro et al., "Micronized/ ultramicronized palmitoylethanolamide displays superior oral efficacy compared to nonmicronized palmitoylethanolamide in a rat model of inflammatory pain," Journal of Neuroinflammation, vol. 11, no. 1, p. 136, 2014.

[57] K. R. Stover, M. A. Campbell, C. M. Van Winssen, and R. E. Brown, "Analysis of motor function in 6-month-old male and female 3xTg-AD mice," Behavioural Brain Research, vol. 281, pp. 16-23, 2015.

[58] S. Oddo, A. Caccamo, M. Kitazawa, B. P. Tseng, and F. M. LaFerla, "Amyloid deposition precedes tangle formation in a triple transgenic model of Alzheimer's disease," Neurobiology of Aging, vol. 24, no. 8, pp. 1063-1070, 2003.

[59] L. M. Billings, S. Oddo, K. N. Green, J. L. McGaugh, and F. M. LaFerla, "Intraneuronal A $\beta$ causes the onset of early Alzheimer's disease-related cognitive deficits in transgenic mice," Neuron, vol. 45, no. 5, pp. 675-688, 2005.

[60] N. A. Castello, K. N. Green, and F. M. LaFerla, "Genetic knockdown of brain-derived neurotrophic factor in 3xTg-AD mice does not alter a $\beta$ or tau pathology," PLoS One, vol. 7, no. 8, article e39566, 2012.

[61] E. R. Nestmann, "Safety of micronized palmitoylethanolamide (microPEA): lack of toxicity and genotoxic potential," Food Science \& Nutrition, vol. 5, no. 2, pp. 292-309, 2017. 


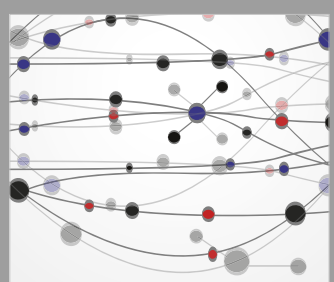

The Scientific World Journal
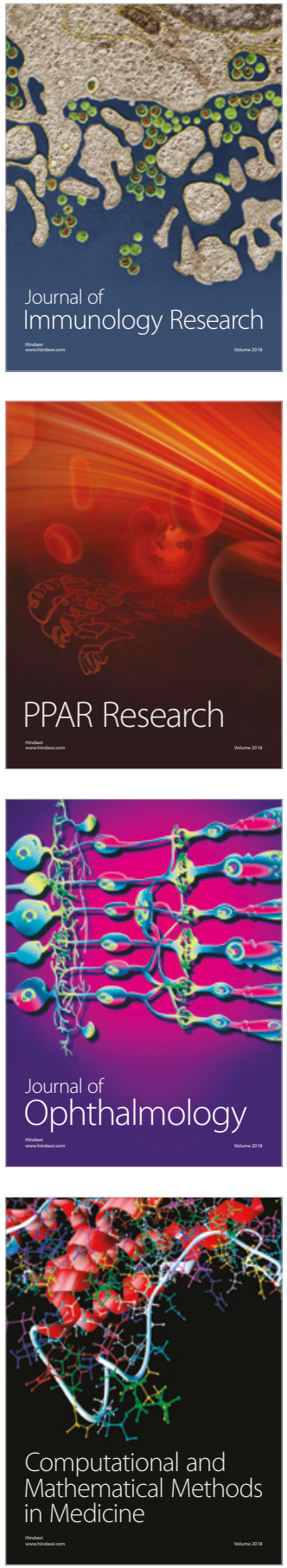

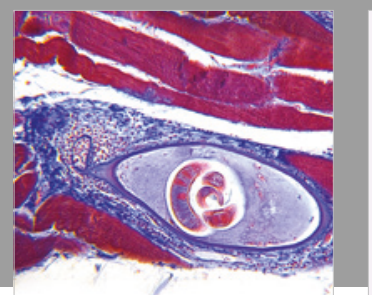

Gastroenterology Research and Practice

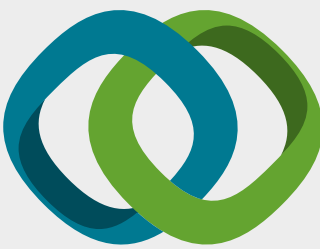

\section{Hindawi}

Submit your manuscripts at

www.hindawi.com
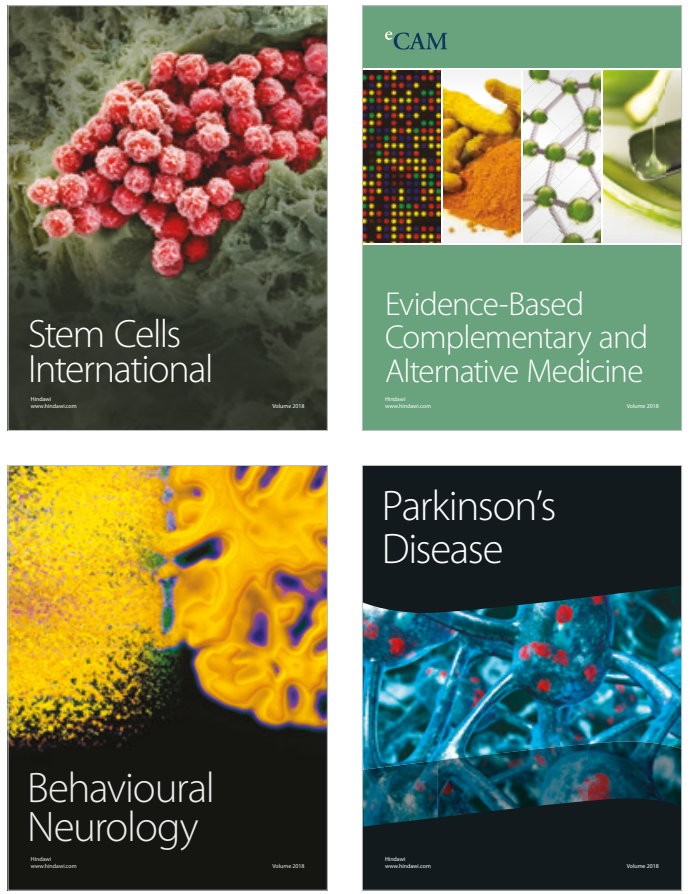

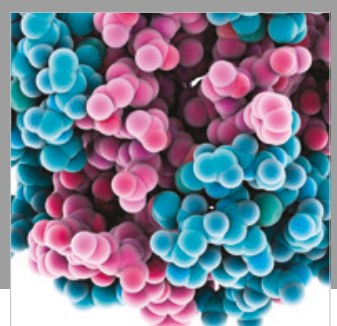

ournal of

Diabetes Research

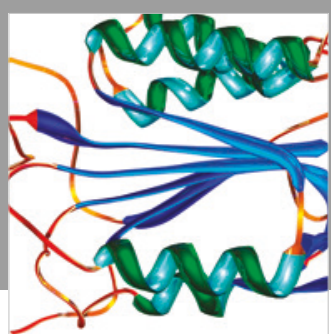

Disease Markers
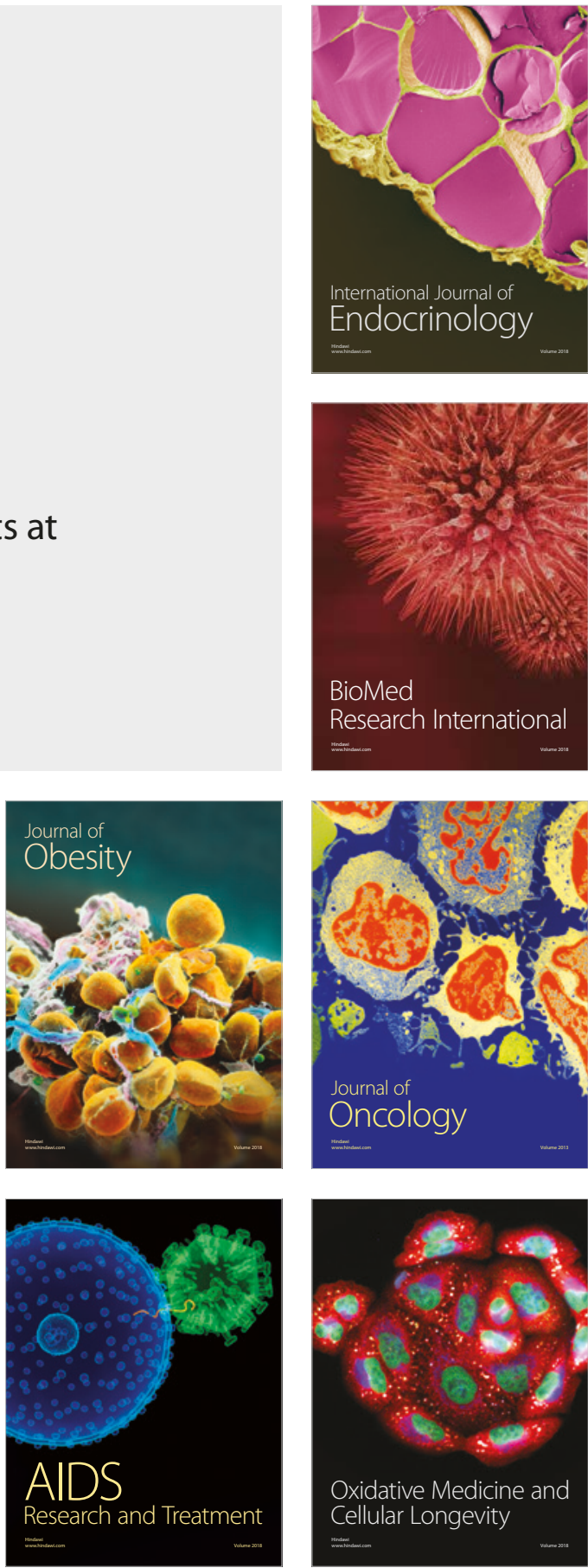